\title{
Are invaders different? A conceptual framework of comparative approaches for assessing determinants of invasiveness
}

\author{
Mark van Kleunen, ${ }^{1 \star}$ Wayne \\ Dawson, ${ }^{1}$ Daniel Schlaepfer, ${ }^{1,2}$ \\ Jonathan M. Jeschke ${ }^{3,4}$ and \\ Markus Fischer ${ }^{1}$ \\ ${ }^{1}$ Institute of Plant Sciences and \\ Oeschger Centre, University of \\ Bern, Altenbergrain 21, CH-3006 \\ Bern, Switzerland \\ ${ }^{2}$ Department of Botany, \\ University of Wyoming, 1000 \\ East University Avenue, Laramie, \\ WY 82071, USA \\ ${ }^{3}$ Department of Biology II, \\ Ludwig-Maximilians-University \\ Munich, Grosshaderner Str. 2, \\ DE-82152 Planegg-Martinsried, \\ Germany \\ ${ }^{4}$ Cary Institute of Ecosystem \\ Studies, Box AB, Millbrook, NY \\ 12545, USA \\ *Correspondence: E-mail: \\ vkleunen@ips.unibe.ch
}

\begin{abstract}
What determines invasiveness of alien organisms is among the most interesting and urgent questions in ecology. In attempts to answer this question, researchers compare invasive alien species either to native species or to non-invasive alien species, and this is done in either the introduced or native ranges. However, inferences that can be drawn from these comparisons differ considerably, and failure to recognize this could hamper the search for determinants of invasiveness. To increase awareness about this issue, we present a framework of the various comparisons that can be used to test for determinants of invasiveness, and the specific questions each comparison can address. Moreover, we discuss how different comparisons complement each other, and therefore should be used in concert. For progress in invasion biology, it is crucial to realize that different comparisons address different biological questions and that some questions can only be answered unambiguously by combining them.
\end{abstract}

\section{INTRODUCTION}

What determines invasiveness of alien organisms is among the most interesting and urgent questions in ecology. Accordingly, research on biological invasions of animals and plants, as well as other groups of organisms, has increased exponentially in the last 50 years (Richardson \& Pyšek 2008). Potential determinants of invasiveness that are frequently studied include introduction history, species traits, and ecological and evolutionary processes. Studies on introduction history ask, for example, whether invasiveness is associated with propagule pressure (i.e. the number of individuals introduced and the frequency of introduction events; Lockwood et al. 2005). Studies on species traits ask, for example, whether invasiveness is associated with fitness or dispersal-related characteristics (Baker 1974). Studies on ecological processes may ask whether invasiveness is associated with release from natural enemies (Crawley 1987), whilst studies on evolutionary processes might ask whether invasiveness of species is associated with evolution of increased competitive ability in the introduced range (Blossey \& Nötzold 1995; Hänfling 2007). These are just some examples of existing hypotheses that are being tested in the search for determinants of invasiveness (for an overview of hypotheses in invasion biology, see Catford et al. 2009). The tests of all these hypotheses require comparative studies. In other words, they require comparisons between organisms differing in invasiveness.

Researchers have been and still are using different types of comparison to test for determinants of invasiveness. Some studies compare invasive alien species to native species, whilst other studies compare them to non-invasive alien species (Jeschke \& Strayer 2006; Pyšek \& Richardson 2007; van Kleunen et al. 2010). For the latter type of comparison with alien species, some studies are conducted in the introduced range and others in the native range (also referred to as the target-area and source-area approaches, respectively, sensu Pyšek et al. 2004). Yet others make 


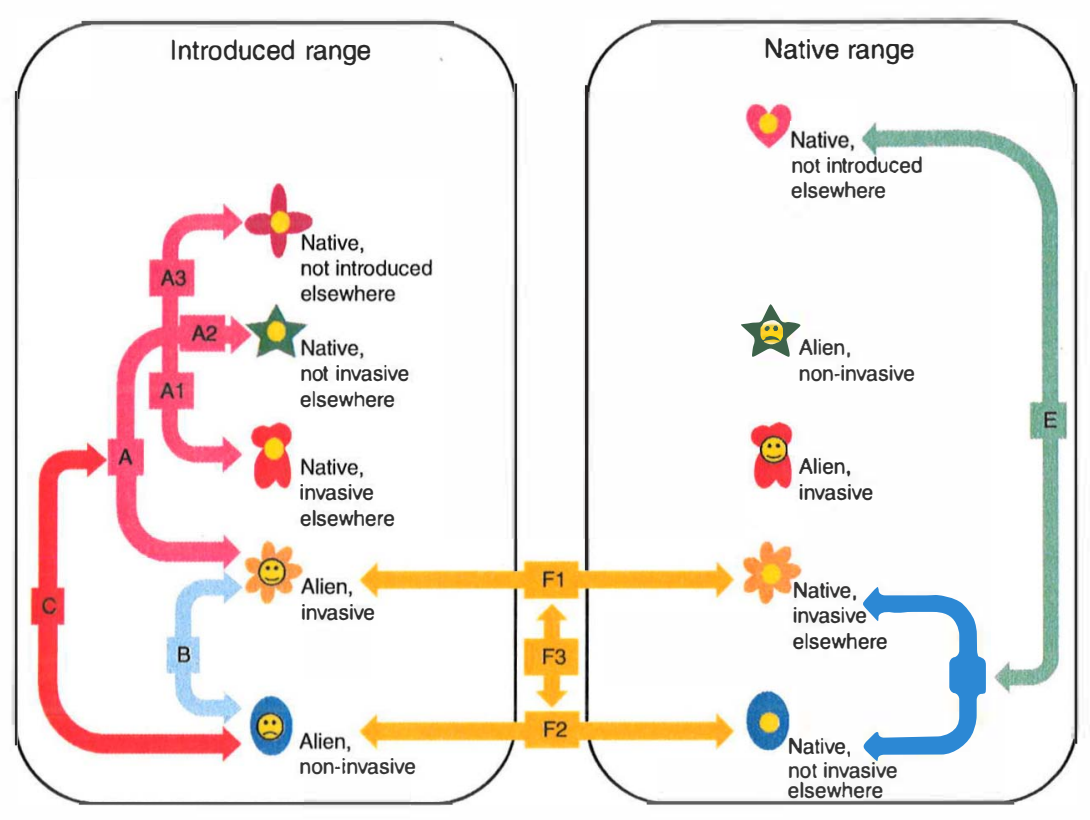

Figure 1 Schematic diagram of the major types of comparison used to assess determinants of invasiveness, when considering introduction and invasiveness of native species elsewhere in the world. In the introduced range (left panel), we can compare invasive alien species to native (A) and non-invasive alien (B) species, and we can compare non-invasive alien to native species (C). The native species can be further subdivided according to whether they have been introduced (A1 and A2 vs. A3) and become invasive (A1 vs. A2) elsewhere in the world. In the native range (right panel), we can compare species that have become invasive elsewhere to species that have not become invasive after introduction elsewhere (I), and we can compare species that have been introduced elsewhere to species that have not been introduced elsewhere (E). For species that have been introduced elsewhere, we can do intraspecific comparisons between the introduced and native ranges ( $\mathrm{F} 1$ for invasive species and $\mathrm{F} 2$ for non-invasive species), and we can compare intraspecific differences between the invasive and noninvasive species (F3). The interpretation of these different comparisons is given in the text.

intraspecific

sons, between populations of invasive species in the native and introduced ranges (see Torchin et al. 2001, 2003 and overviews in Bossdorf et al. 2005; Hierro et al. 2005).

It is encouraging that different comparative approaches are used, because they provide different insights into potential determinants of invasiveness. However, it is not always appreciated that the type of comparison can fundamentally alter the inferences that can be drawn and consequently the hypotheses tested (Figs 1 and 2). Failure to recognize these differences could seriously hamper progress in the search for determinants of invasiveness. Therefore, it is of the utmost importance that we correctly interpret the outcomes of the different comparative approaches, and that we use the appropriate comparisons for our specific hypotheses. Moreover, the different comparative approaches are still rarely used in concert, although doing so would allow us to gain a more complete insight into the causes of invasiveness.

Several authors have pointed out differences between some of the comparative approaches (e.g. Mack 1996;
Blackburn \& Duncan 2001; Cassey et al. 2004a; Pyšek et al. 2004; Hamilton et al. 2005; Muth \& Pigliucci 2006; Jeschke \& Strayer 2006; Pyšek \& Richardson 2007; Blackburn \& Jeschke 2009; Schlaepfer et al. 2010; van Kleunen et al. 2010). However, a conceptual framework of comparisons concerning determinants of invasiveness is still lacking. Therefore, we summarize here the different types of comparison that can be used to test for determinants of invasiveness of alien species, and some of the specific questions each of them can address (Fig. 1; Table 1). Moreover, we discuss how different comparative approaches complement each other, and therefore should be more frequently used in concert. We restrict our discussion of comparative approaches to issues that are specific to studies on invasiveness, and do not discuss more general issues of comparative studies, such as whether or not to correct for phylogeny or taxonomy (e.g. Westoby et al. 1995). We also do not aim to review all hypotheses and do not suggest which ones might be the most important ones. The framework may provide guidance for selecting the right comparator(s) for any hypothesis on the causes of invasiveness. 


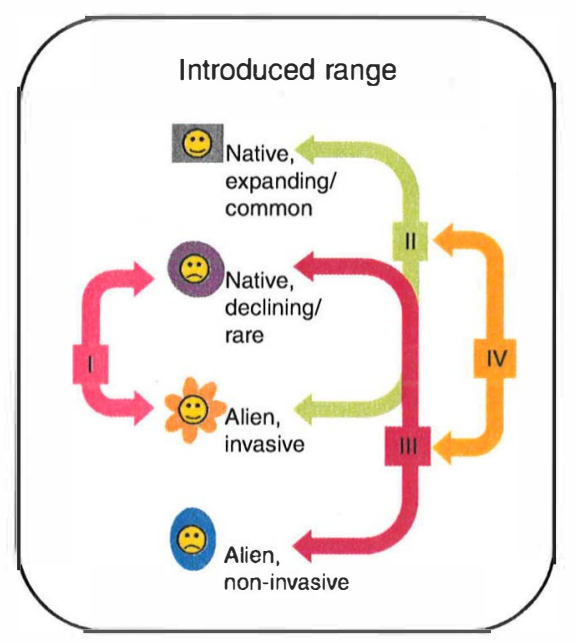

Figure 2 Schematic diagram of the major types of comparison used to assess determinants of invasiveness, when considering abundance or distribution of native species at home. Comparison I tests which traits and processes give invasive alien species an advantage over rare native species. Comparison II tests whether traits and processes differ between invasive alien species and common native species. Comparison III tests whether traits and processes differ between non-invasive alien species and rare native species. Comparison IV tests whether traits and processes differ between common and rare species, irrespective of whether they are native or alien.

\section{COMPARISONS IN THE INTRODUCED RANGE OF INVASIVE SPECIES}

In the introduced range of invasive alien species, we can compare them to native species (comparison A in Fig. 1) and to non-invasive alien species (comparison B in Fig. 1). Both types of comparison are used to test for determinants of invasiveness (Table 1), but experimental studies, which are mostly restricted to plants, most frequently use invasive alien vs. native comparisons (Pyšek \& Richardson 2007; van Kleunen et al. 2010). A third possible comparison in the introduced range is the one between non-invasive alien and native species (comparison C in Fig. 1; Lake \& Leishman 2004). Although this comparison does not test directly for determinants of invasiveness, it might yield important additional insights into whether observed differences between invasive alien and native species reflect true determinants of invasiveness rather than general differences between alien and native species (Table 1).

\section{Potential inferences from invasive alien vs. native species comparisons in the introduced range}

Most frequently, the comparison between invasive alien and native species (comparison A in Fig. 1) aims to determine which traits and which ecological and evolutionary processes give invasive alien species an advantage over native species (Hamilton et al. 2005). This type of comparison is frequently used in studies testing the enemy-release hypothesis or studies investigating traits associated with invasiveness (Table 1). Nevertheless, as we explain below, it is often not made explicit that the choice of native species used and the spatial scale (local or global) considered in such comparisons will dictate the inferences that can be drawn.

Frequently, native species are considered as non-invasive control species. However, some of the native control species are themselves introduced and even invasive elsewhere in the world (Fig. 1; Rejmánek 1999); Muth \& Pigliucci 2006). Thus, if the objective of a study is to assess potential determinants of invasiveness at a global scale, studies comparing invasive alien species to native species that are alien invaders elsewhere (comparison A1 in Fig. 1) might not find differences in traits and processes as a result. Indeed, a recent meta-analysis revealed significant differences in trait values between invasive alien plants and native plants overall, but such differences were not significant any longer when limited to those native plant species known to be invasive elsewhere (van Kleunen et al. 2010). Although it is likely that the traits that determine invasiveness differ between environments and between the stages of an invasion, traits may nevertheless be associated with invasiveness at a global scale because some of them are important for survival and reproduction in a wide range of environments (e.g. phenotypic plasticity and ability for uniparental reproduction) or are advantageous in the most common types of invaded environments (e.g. fast growth in disturbed habitats).

On the other hand, if the objective of a study is to assess potential determinants of invasiveness at a local scale, studies comparing invasive alien with native species that are invasive elsewhere may still provide insights into determinants of invasiveness (but see next paragraph). Moreover, such studies could provide insights into determinants of invasiveness at a global scale if they would also include a group of widely introduced native species that are not invasive elsewhere in the world (i.e. this would include comparison A2 in Fig. 1, and would be an invasive alien vs. non-invasive elsewhere comparison). Therefore, when choosing the comparators or set of comparators, the spatial scale of interest should be considered.

Apart from their spread elsewhere in the world (i.e. at a global scale), native species can also vary widely in abundance and distribution at home (i.e. at a local scale). As a result, an alternative to the global-scale categorization of native species into 'not introduced elsewhere', 'non-invasive alien elsewhere' and 'invasive alien elsewhere' (Fig. 1) is the local-scale categorization into expanding/common and declining/rare species in the native range (Fig. 2). This is another important categorization of native species that is 
Table 1 Types of comparison that can be made in invasion biology (see Fig. 1) with examples of questions and hypotheses that can be posed within these comparisons

\begin{tabular}{|c|c|c|}
\hline Type of comparison & Example of question & References \\
\hline \multicolumn{3}{|l|}{ Within introduced range } \\
\hline \multirow[t]{4}{*}{$\begin{array}{l}\text { (A) Invasive alien vs. } \\
\text { native }\end{array}$} & $\begin{array}{l}\text { ERH: Do invasive species suffer less from natural enemies than } \\
\text { native species? }\end{array}$ & $\begin{array}{l}\text { Liu \& Stiling (20)6), Dang et al. } \\
(2009)\end{array}$ \\
\hline & LH: Do invasive species have different traits than native species? & $\begin{array}{l}\text { Leishman et al. (2010), Tecco et al. } \\
\text { (2010), van Kleunen et al. (2010) }\end{array}$ \\
\hline & PhP: Are invasive species more phenotypically plastic than natives? & Richards et al. $(2006)$ \\
\hline & $\begin{array}{l}\text { FR: Are invasive species better able to capitalize on free resources } \\
\text { (e.g. disturbances) than the native species pool of invaded } \\
\text { communities? }\end{array}$ & Davis et al. $(200())$ \\
\hline \multirow[t]{7}{*}{$\begin{array}{l}\text { (B) Invasive alien vs. } \\
\text { non-invasive alien }\end{array}$} & $\begin{array}{l}\text { ERH: Do invasive species benefit from enemy release more than } \\
\text { non-invasive species? }\end{array}$ & $\begin{array}{l}\text { Dawson et al. }(2009 \mathrm{a}) \text {, van Kleunen } \\
\text { \& Fischer }(20(09)\end{array}$ \\
\hline & $\begin{array}{l}\text { DNH: Are invasive species less phylogenetically related to native } \\
\text { species than non-invasive species? }\end{array}$ & $\begin{array}{l}\text { Strauss et al. (2006), Diez et al. } \\
(2008)\end{array}$ \\
\hline & $\begin{array}{l}\text { PP/RT: Are invasive species introduced in greater numbers or earlier } \\
\text { than non-invasive species? }\end{array}$ & $\begin{array}{l}\text { Cassey et al. }(20(0) 4 \mathrm{~b}), \text { Bucharova \& } \\
\text { van Kleunen }(20(0))\end{array}$ \\
\hline & $\begin{array}{l}\text { LH: Do invasive species have different traits than non-invasive } \\
\text { species? }\end{array}$ & $\begin{array}{l}\text { Blackburn et al. }(2009) \text {, van } \\
\text { Kleunen et al. }(2010)\end{array}$ \\
\hline & $\begin{array}{l}\text { LH: Do invasive species have a greater fitness and intrinsic rate of } \\
\text { increase than non-invasive species? }\end{array}$ & Burns $(2008)$ \\
\hline & $\begin{array}{l}\text { PhP: Are invasive species more phenotypically plastic than } \\
\text { non-invasive species? }\end{array}$ & Richards et al. $(2006)$ \\
\hline & $\begin{array}{l}\text { FR: Are invasive species better able to capitalize opportunistically on } \\
\text { increased resource availability than non-invasive species? }\end{array}$ & Davis et al. $(200)$ ) \\
\hline $\begin{array}{l}\text { (C) Non-invasive } \\
\text { alien vs. native }\end{array}$ & $\begin{array}{l}\text { LH: Do the traits that distinguish invasive alien from native species } \\
\text { also distinguish non-invasive from native species, which would } \\
\text { indicate an introduction bias? }\end{array}$ & $\begin{array}{l}\text { Chrobock, Kempel, Fischer \& van } \\
\text { Kleunen, unpublished data }\end{array}$ \\
\hline \multicolumn{3}{|l|}{ Within native range } \\
\hline $\begin{array}{l}\text { (D) Invasive vs. } \\
\text { non-invasive } \\
\text { elsewhere }\end{array}$ & $\begin{array}{l}\text { LH: Do invasive species differ in their traits from non-invasive } \\
\text { species before introduction? }\end{array}$ & $\begin{array}{l}\text { Jeschke \& Strayer }(2006) \\
\text { Schlaepfer et al. }(2010)\end{array}$ \\
\hline $\begin{array}{l}\text { (F) Introduced vs. } \\
\text { non-introduced } \\
\text { elsewhere }\end{array}$ & $\begin{array}{l}\text { LH: Is there a bias towards introduction of species with specific } \\
\text { traits? }\end{array}$ & $\begin{array}{l}\text { Colautti (2005), Jeschke \& Strayer } \\
(2006), \text { van Kleunen et al. }(2007)\end{array}$ \\
\hline \multicolumn{3}{|c|}{ Between introduced and native ranges } \\
\hline \multirow{2}{*}{$\begin{array}{l}\text { (F1) Introduced vs. } \\
\text { native range of } \\
\text { invasive species }\end{array}$} & $\begin{array}{l}\text { ERH: Do invasive species in their native range suffer more from } \\
\text { natural enemies than in their introduced range? }\end{array}$ & $\begin{array}{l}\text { Torchin et al. }(20() 1,20() 3) \text {, } \\
\text { DeWalt et al. }(20(04)\end{array}$ \\
\hline & $\begin{array}{l}\text { Do invasive species undergo evolutionary change after introduction? } \\
\text { (e.g. EICA) }\end{array}$ & Bossdorf et al. (2005) \\
\hline $\begin{array}{l}\text { (F2) Introduced vs. } \\
\text { native range of } \\
\text { non-invasive } \\
\text { species }\end{array}$ & $\begin{array}{l}\text { Do non-invasive species not undergo evolutionary change after } \\
\text { introduction? (e.g. EICA) }\end{array}$ & None \\
\hline $\begin{array}{l}\text { (F3) Introduced vs. } \\
\text { native range }\end{array}$ & $\begin{array}{l}\text { ERH: Are invasive species released more from natural enemies than } \\
\text { non-invasive species? }\end{array}$ & $\begin{array}{l}\text { Mitchell \& Power (2003), } \\
\text { van Kleunen \& Fischer (20(0)) }\end{array}$ \\
\hline $\begin{array}{l}\text { comparisons } \\
\text { between invasive } \\
\text { and non-invasive } \\
\text { species (F1 vs. F2) }\end{array}$ & $\begin{array}{l}\text { Do invasive species evolve more after introduction than } \\
\text { non-invasive species? (e.g. EICA) }\end{array}$ & None \\
\hline
\end{tabular}

Hypotheses are: ERH, enemy-release hypothesis; LH, life-history hypothesis; PhP, phenotypic-plasticity hypothesis; DNH, Darwin's naturalization hypothesis; PP/RT, propagule-pressure/residence-time hypothesis; EICA, evolution-of-increased-competitive-ability hypothesis; $\mathrm{FR}$, hypothesis of fluctuating resources and invasibility. Lpper case letters in brackets correspond to the different comparisons in Fig. 1. Note that the hypotheses, questions and examples are not exhaustive. 
rarely made when comparing invasive alien species to native species (Thompson et al. 1995; van Kleunen \& Richardson 2007; Jeschke \& Strayer 2008; Blackburn \& Jeschke 2009; Leishman et al. 2010).

Studies using invasive alien vs. native species comparisons frequently implicitly assume that invasive alien species do better than all co-occurring native species (comparison I in Fig. 2). Studies comparing invasive alien species (i.e. abundant alien species) to native species irrespective of the abundance of the latter might find

differ on average from the native species as is the case in Fig. 3. However, comparisons of invasive alien species to common or expanding native species (comparison II in Fig. 2) - some of which might even be considered 'invasive' native species (Alpert et al. 2000) - might not reveal differences, because the traits and ecological and evolutionary processes that determine the success of both types of species may be the same (Fig. 3a; Thompson et al. 1995; van Kleunen \& Richardson 2007; Leishman et al. 2010). Thus, a study finding differences between invasive alien species and native species may not contradict another study that does
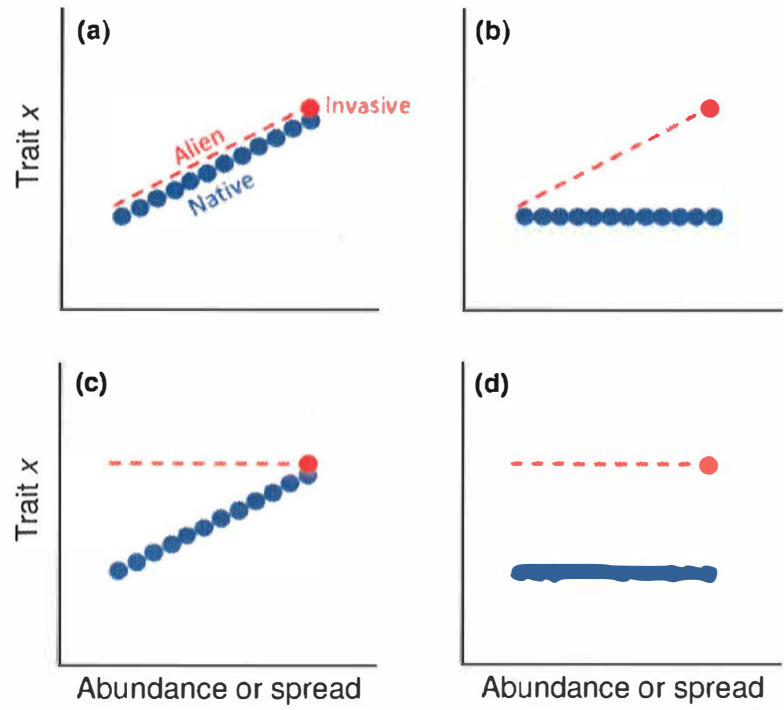

Figure 3 Conceptual plots illustrating the importance of considering success (i.e. abundance or spread) of the native species in invasive alien vs. native species comparisons. All plots (a-d) show that the invasive (i.e. abundant) alien species (red dot) differ in trait $x$ from most of the native species (blue dots). When, however, we consider abundance or spread of alien species (i.e. include less invasive and non-invasive alien species; dashed red line) and of native species, we might find that trait $x$ drives success of both alien and native species (a), drives success of the alien species only (b), drives success of the native species only (c), distinguishes alien from native species but does not drive their success (d). A quantitative example illustrating the importance of considering success of both the alien and the native species is given in Appendix S1. not find

congruous, if the first study used rare and/or declining native species (comparison II in Fig. 2) and the second one used common and/or expanding native species (comparison $I$ in Fig. 2). On the other hand, differences in traits and ecological and evolutionary processes between invasive alien and expanding native species would indicate that the determinants of invasiveness differ between alien and native species (Fig. 3b) or that all alien species differ from native species irrespective of their abundances (Fig. 3d). Another possibility is that a trait is related to the abundance of the native species but not to the abundance of the alien species (Fig. 3c). We found such a scenario in a quantitative analysis of height between 223 native and 77 alien species of Asteraceae varying in their abundance in Germany (Appendix S1). Overall, these considerations imply that not all studies comparing invasive alien to native species provide a clear insight into which traits and processes give invasive alien species an advantage over native species. An understanding of why invasive aliens have such an advantage could be gained by comparing them to those native species that have declined in or disappeared from the invaded community or region (comparison I in Fig. 2).

In addition to the considerations above, the choice of the native control species should also depend on the spatial scale at which the species co-occur. For example, when investigating whether or not the success of alien invasive over native species is due to alien enemy release, it would be meaningless to choose native comparators that do not occur in close proximity to alien species with no potential for interaction. On the other hand, when testing why some species (either native or alien) are expanding in a larger region whilst others are not, and whether the underlying traits and processes differ between native and alien species, co-occurrence of the species is not a necessary prerequisite. For example, if alien plant or animal species but no native species are invading disturbed sites (i.e. they do not co-occur at a small local scale), it is still important to know why native species that occur in the wider region do not invade these disturbed sites. An example of a relevant question would then be whether invasive aliens are better able to capitalize resources that become available after disturbance than natives (Davis $e t$ al. 2000). Thus, studies comparing invasive alien species and native species should clearly formulate which hypotheses are being tested, in which environments, at which spatial scale, and how the native comparators are selected.

\section{Potential inferences from invasive vs. non-invasive alien species comparisons in the introduced range}

Comparisons between invasive and non-invasive alien species (comparison B in Fig. 1) ask why some alien species become invasive and others fail to do so. If one further 
divides the invasive and non-invasive species into several subcategories, one can additionally test whether the different stages of the invasion process are associated with different traits and ecological and evolutionary processes. For example, distinctions can be made between introduced alien species that never occur outside of captivity or cultivation, species that occasionally escape but fail to establish (i.e. are casuals), species that have naturalized, selfsustaining populations, and invasive species spreading in the landscape (Richardson et al. 2000; Cassey et al. 2004a; Colautti \& MacIsaac 2004; Dietz \& Edwards 2006; Jeschke \& Strayer 2006; Dawson et al. 2009)b).

Comparing invasive and non-invasive alien species in the introduced range is, at least at first sight, a straightforward approach to test whether traits and ecological and evolutionary processes are associated with invasiveness of alien species. However, potential limitations of this approach that should be kept in mind are that some currently non-invasive alien species might not have reached their full invasion potential yet due to differences in introduction history. They could still be in their so-called 'lag-phase' because they have been introduced recently, at low frequency, with low levels of genetic variation or in unsuitable environments (Kowarik 1995; Lockwood et al. 2005). If this is the case, the intrinsic invasiveness of the invasive and non-invasive species might not differ. Therefore, if information on the introduction history of alien species is available, one should explicitly test its importance for current invasiveness status (Table 1), and account for it when testing for differences in traits and ecological and evolutionary processes between invasive and non-invasive alien species (Blackburn \& Duncan 2001; Dehnen-Schmutz et al. 2007; Gravuer et al. 2008; Bucharova \& van Kleunen 2009).

The approach of comparing alien species differing in invasiveness is the most direct test of determinants of invasiveness. Although this comparative approach has been used in database studies (e.g. Pyšek et al. 1995; Blackburn \& Duncan 2001; Cassey et al. 2004a; Jeschke \& Strayer 2006, 2008; Blackburn \& Jeschke 2009), it is still rarely used in comparative experiments, most likely because it is difficult to find individuals of non-invasive species in the introduced range (Pyšek \& Richardson 2007; van Kleunen et al. 2010). In addition, the paucity of historical records available for species failing to establish and naturalize in introduced ranges often limits the focus of investigation to later stages of invasion (Kolar \& Lodge 2001). Nevertheless, comparisons are possible if one uses non-invasive species that have established a few naturalized populations (Lake \& Leishman 2004; Leishman \& Thomson 2005) or if one would use alien organisms that are commercially sold in the introduced range. The choice of the type of non-invasive alien comparator used will ultimately depend on the hypothesis being tested.

\section{Potential inferences from non-invasive alien vs. native species comparisons in the introduced range}

Differences between invasive alien and native species could reflect biased introductions of alien species with specific characteristics that do not play a role in invasiveness (Fig. 3c,d). Such an introduction bias is particularly likely for plants and vertebrates given that the majority of these invasive alien organisms have been introduced intentionally, because they have particular characteristics that make them attractive for ornamental, agricultural or silvicultural purposes, or in the case of vertebrates for husbandry, hunting and fishing (Blackburn \& Duncan 2001; Cassey et al. 2004a; Jeschke \& Strayer 2006, 2008; Hulme et al. 2008; Blackburn \& Jeschke 2009).

One way to differentiate between these possibilities is to test whether the traits and processes that distinguish invasive alien species from native species also distinguish non-invasive alien species from native species (comparison $\mathrm{C}$ in Fig. 1; Table 1). A recent study comparing germination properties of 43 species native to Switzerland and 46 related non-invasive alien species introduced there for ornamental purposes found that the alien species had faster and more profuse seed germination on average (Chrobock, Kempel, Fischer \& van Kleunen, unpublished data). Similarly, studies have frequently reported that invasive aliens have faster and more profuse seed germination than native species (e.g. Pyšek \& Richardson 2007; Flory \& Clay 2009). Combining these findings exemplifies that introduced alien species might differ from native species even when they are not invasive. A potential limitation of comparisons between invasive alien and native species is that they may not reveal determinants of invasiveness if there is such an introduction bias. Therefore, comparisons between invasive alien and native species are most informative when combined with a comparison to noninvasive alien species, and particularly when they also distinguish between rare and common native species (Fig. 3, Appendix S1).

\section{COMPARISONS IN THE NATIVE RANGE OF INVASIVE SPECIES}

In the native range of invasive species, we have a nested set of two comparisons. First, among the species introduced to a new region or a specific environment, one can compare species that have become invasive to species that have not become invasive (comparison $D$ in Fig. 1) to test for determinants of invasiveness. Second, one can compare species that have been introduced elsewhere to species that have not been introduced elsewhere (comparison $\mathrm{E}$ in Fig. 1) to test whether there is an introduction bias. 


\section{Potential inferences from invasive vs. non-invasive alien comparisons in the native range}

Besides comparing invasive and non-invasive alien species in their introduced range (comparison B in Fig. 1), they can also be compared in their common native range (comparison D in Fig. 1). These two types of comparison are not direct substitutes of each other because the inferences that can be drawn from the native-range and introduced-range approaches differ. This is probably most obvious for ecological processes such as the ones involving interactions with enemies that may differ between native and introduced ranges. However, trait differences, as measured under common environmental conditions, may also depend on whether native or introduced organisms were used. Trait differences between invasive alien and non-invasive alien species in the introduced range (comparison B in Fig. 1; see previous section) could reflect either differences that were already present at the moment of introduction or differences that evolved during or after introduction of the species. Similarly, a lack of trait differences could suggest that differences were not present between species at the moment of introduction or that differences disappeared due to evolution. In contrast, differences between invasive and non-invasive alien species in their native range most likely reflect differences that were present at the moment of introduction elsewhere (Table 1). This reasoning of course relies on the assumption that invasive and non-invasive species did not undergo major evolutionary change in their native range as they were introduced elsewhere. If this assumption holds, such studies can reveal traits that increase the likelihood of alien species to become invasive elsewhere (Jeschke \& Strayer 2006; Schlaepfer et al. 2010). However, because the importance of traits for invasiveness may depend on the environment, it is important that such studies include a wide range of environmental conditions. The results of studies comparing invasive and non-invasive alien species in their native range could be particularly informative for risk assessment, because these traits can be assessed on organisms that have not been introduced elsewhere yet but are considered for intentional introduction.

The difference in interpreting database studies using invasive vs. non-invasive alien comparisons in the introduced range and studies using these comparisons in the native range relies on whether the data were actually collected in the respective ranges. This is, however, not always the case. For example, some frequently used databases, such as the BiolFlor database containing ecological traits of the German flora (Klotz et al. 2002) also include data sources from other European regions and even from other continents. Similarly, some experimental studies comparing invasive and non-invasive alien species in their introduced range used seed material from the native range for some species (e.g. Muth \& Pigliucci 2006). 'The database used by Jeschke \& Strayer (2006) to assess determinants of vertebrate invasiveness in Europe and North America made comparisons both in the introduced and native range, but the data predominantly came from the native range. It is likely that collection of data in the native range or on material from the native range is biased towards alien species that are not or only mildly invasive in their introduced range. In contrast, data for widely introduced and invasive species are more likely to be collected in the introduced range. Consequently, such studies do not allow strict testing of whether invasive and non-invasive alien species differ also in their introduced range or whether they differed already in their native range.

\section{Potential inferences from elsewhere introduced vs. non-introduced comparisons in the native range}

The comparison between species introduced elsewhere, irrespective of whether they have become invasive, and species that have not been introduced elsewhere (comparison $E$ in Fig. 1) tests whether there is a bias towards introduction of species with certain characteristics (Table 1). Such potential biases in species introductions have been suggested as explanations for why invasive vertebrates have large native ranges (Blackburn \& Duncan 2001; Jeschke \& Strayer 2006), and why invasive alien plant species apparently possess certain characteristics such as fast growth, shade intolerance and small seed size (Martin et al. 2009). Therefore, the comparison of species in their native range that are introduced elsewhere in the world with those that are not introduced elsewhere could provide important insights into whether apparent characteristics of invasive species are truly associated with invasiveness rather than a consequence of introduction bias. Existing studies that have used this type of comparison showed that there can be an introduction bias towards species with characteristics that have frequently been reported to be associated with invasiveness (Blackburn \& Duncan 2001; Colautti 2005; Jeschke \& Strayer 2006; van Kleunen et al. 2007). The main restriction on this type of comparison is the lack of data on which species have been introduced elsewhere. However, for species intentionally introduced as amenities, ornamentals, or food source, their availability from international commercial seed suppliers, pet stores, or food markets might be a good proxy for introduction elsewhere (Chapman et al. 2003; Cassey et al. 2004a; van Kleunen et al. 2007).

\section{COMPARISONS BETWEEN NATIVE AND INTRO- DUCED RANGES}

Intraspecific comparisons between introduced and native ranges of invasive alien species (comparison F1 in Fig. 1) 
might also provide important insights into determinants of invasiveness (Hierro et al. 2005). Such an intraspecific, biogeographical comparative approach has most frequently been applied to test the enemy-release hypothesis (Torchin et al. 2003; reviewed in Colautti et al. 2004; Liu \& Stiling $2006)$ and hypotheses of genetic and/or ecological changes (Ellstrand \& Schierenbeck 2000); Cox 2004; Huey et al. 2005; Schlaepfer et al. 2008; Table 1), for instance the evolutionof-increased-competitive-ability (EICA) hypothesis (see below). As pointed out by Hierro et al. (2005), the biogeographical approach could also be used to test other hypotheses, such as the novel weapons (e.g. Callaway \& Aschehoug 2000) and Darwin's naturalization (e.g. Strauss et al. 2006; Diez et al. 2008) hypotheses, which are usually only tested in the introduced range.

The biogeographical approach might provide even more insights into determinants of invasiveness if it would not be restricted to highly invasive alien species but would also include non-invasive or less invasive alien species (comparison F2 in Fig. 1). For example, most biogeographical studies testing the enemy-release hypothesis showed that invasive species have fewer enemies in their introduced ranges than in their native ranges (Torchin et al. 2003; Liu \& Stiling 2006; van Kleunen \& Fischer 2009)). However, if non-invasive alien species are also released from their enemies to the same extent as invasive alien species, then enemy release cannot be the mechanism responsible for differences in invasiveness (Lake \& Leishman 2004; van Kleunen \& Fischer 2009). Therefore, interspecific comparisons of intraspecific differences between the native and introduced ranges of alien species are required (comparison F3 in Fig. 1; Table 1).

Several biogeographical studies have compared trait values of invasive species measured in their introduced range to those measured in their native range, using data from floral compendia (e.g. Thébaud \& Simberloff 2001), databases (e.g. Daws et al. 2007), published studies (e.g. Mason et al. 2008) and direct measurements (e.g. Torchin et al. 2001; Buckley et al. 2003). Although such studies have revealed intriguing differences between traits of species in their introduced and native ranges, they do not reveal whether the underlying mechanism for change is phenotypic plasticity, a founder effect (i.e. an introduction bias), adaptive post-introduction evolution or a combination of these mechanisms. This would require experiments with individuals from both ranges under common environmental conditions, preferably replicated in both ranges as reciprocal translocation experiments (Moloney et al. 2009).

In plants, common-garden experiments using both native and introduced material of invasive species have frequently been conducted to test the EICA hypothesis (Table 1). This hypothesis postulates that due to a lack of natural enemies in the introduced range, as predicted by the enemy-release hypothesis, invasive organisms may have evolved a higher competitive ability (i.e. larger size and/or fecundity) at the cost of resistance to enemies (Blossey \& Nötzold 1995; reviewed in Bossdorf et al. 2005). Although the EICA hypothesis has only been tested for plants, it should also apply to other organisms (Hänfling 2007). Moreover, such common-environment studies could also be used to test whether other traits, such as body size (Huey et al. 2005), phenotypic plasticity (Richards et al. 2006) or traits related to self-fertilization (van Kleunen \& Fischer 2008), show genetic differentiation between the introduced and native ranges.

Studies finding trait differences between introduced and native accessions grown under common environmental conditions frequently claim that adaptive evolution is an important determinant of invasiveness. However, most of these studies cannot distinguish between adaptive evolutionary changes (i.e. responses to selection) and non-adaptive ones (i.e. genetic drift including founder effects). To test for the latter, studies should also check for neutral genetic differentiation using molecular markers (Maron et al. 2004; Keller \& Taylor 2008; van Kleunen \& Fischer 2008). In many such studies, differences could reflect maternal environmental carry-over effects, which could be avoided by using second-generation offspring (Moloney et al. 2009)). Furthermore, to test whether evolutionary change is a driver of invasiveness, invasive and non-invasive or less invasive species should be compared (comparison F3 in Fig. 1). To the best of our knowledge, there have as yet been no tests on evolutionary change in non-invasive or mildly invasive species (Table 1).

\section{COMPLEMENTARITY OF DIFFERENT COMPARATIVE APPROACHES}

Studies testing for determinants of invasiveness usually use one single comparator or group of comparators, and frequently do not make explicit the criteria used to select the non-invasive comparators. Consequently, it is not always clear whether the comparison made is appropriate to address the questions posed. The latter partly depends on the spatial scale of the investigation (Figs 1 and 2). Moreover, as pointed out in the previous sections, some questions in invasion ecology require multiple comparisons to unambiguously assess determinants of invasiveness.

In the introduced range, traits and ecological and evolutionary processes differing between invasive alien species and native species might indicate why invasive alien species have an advantage over native species. However, if these traits and processes do not differ between invasive and non-invasive alien species, these traits and processes might simply reflect an introduction bias, and might thus not 
reveal true determinants of invasion. Alternatively, it could be that invasive and non-invasive alien species did not differ in the traits and processes under the specific environmental conditions that they were measured, but that they do differ when measured under other environmental conditions. Nevertheless, combining the invasive alien species vs. native species comparison with the invasive vs. non-invasive alien species comparison could provide insights that each of them separately would not. Moreover, if one wants to test explicitly whether the traits and processes that differentiate invasive from non-invasive alien species are the same ones that differentiate common from rare native species (van Kleunen \& Richardson 2007; Jeschke \& Strayer 2008; Blackburn \& Jeschke 2009), one also has to compare these four groups of species in a single study. Such comparisons could reveal that invasive alien species differ from the average native species, but that invasive alien species do not differ from common native species (Fig. 3, see also example in Appendix S1).

Comparisons of invasive and non-invasive alien species in their native range can reveal traits and processes that increase the likelihood of alien species becoming invasive elsewhere. If one compares these two groups of species, which both have been introduced elsewhere, to a third group of species that have not been introduced elsewhere, we can assess the importance of introduction bias (Colautti 2005; Jeschke \& Strayer 2006; van Kleunen et al. 2007). In addition, one can test whether the traits and processes associated with species introduced elsewhere are the same as the ones that confer invasiveness once introduced elsewhere (Colautti 2005; Jeschke \& Strayer 2006; van Kleunen et al. 2007). For risk assessment, it would be particularly informative to know whether species intentionally introduced by humans elsewhere, for example, for ornamental or hunting purposes, have been selected for traits that also confer invasiveness.

Comparisons between introduced and native ranges have been usually restricted to highly invasive species. If we combine this intraspecific

interspecific comparison between invasive and non-invasive species, we would be able to test whether the traits and processes differing between introduced and native ranges are truly driving invasiveness. To the best of our knowledge, this joint approach has only been used to test whether release of alien plants from pathogens is associated with invasiveness (Mitchell \& Power 2003; van Kleunen \& Fischer 2009). We therefore suggest that future studies comparing traits and processes between introduced and native ranges or accessions should not be restricted to highly invasive species. This would increase our understanding of why certain alien species become invasive (comparisons B and $D$ in Fig. 1), and would identify whether alien species were predisposed to become invasive before introduction or if they changed at or after introduction and became invasive (comparison F3 in Fig. 1).

One aspect that has received relatively little attention in comparisons of invasive alien species to others is that there might be an introduction bias towards species with certain characteristics and that this could result in erroneous conclusions regarding determinants of invasiveness. Mainly the literature on vertebrates, especially on birds, has highlighted this potential problem (Blackburn \& Duncan 2001; Cassey et al. 2004a; Jeschke \& Strayer 2006; Blackburn \& Jeschke 20(9)). Above, we discussed two types of introduction biases. One type of introduction bias is that most alien species that have been introduced, irrespective of their invasiveness, deviate on average from the native species, which is very likely. As a consequence, invasive alien vs. native comparisons may reveal differences that are not informative with regard to the causes of invasiveness when the invasive and non-invasive alien species do not differ. This means that it is necessary to also include non-invasive alien species in the comparison. Second, there may also be an introduction bias within the pool of potential alien species for certain characteristics, such as fast growth rate and generalist feeding; the species that are actually introduced elsewhere are not a random sample of all potential species that could be introduced from a given source range. As a result, multiple types of comparison are required to test the nature of potential introduction biases that might lead to spurious conclusions or obscure true determinants of invasiveness.

\section{CONCLUSIONS}

The comparative framework that we propose could in principle be applied to any group of organisms. If the specific hypothesis to be tested requires common-environment studies, comparisons have mainly been restricted to plant species, and particularly to short-lived herbaceous species or to the early ontogenetic stages of long-lived trees (Grotkopp \& Rejmánek 2007). However, if we cannot easily grow long-lived plant species in common-garden experiments, we can compare them under near-common environmental conditions in field

to naturally co-occur (Leishman et al. 2010; Tecco et al. 2010), in forest plantations (Richardson et al. 2004) or in botanical gardens (Dawson et al. 2009a,b). For animals, common-environment studies comparing invasive alien species to native or non-invasive alien ones are relatively rare, although there are some examples (Lee et al. 2005; Engel \& Tollrian 2009); Larson \& Magoulick 2009)). Laboratory conditions are too artificial for some animals to allow for meaningful experiments, but such experiments should still be feasible for other animals, e.g. for small aquatic animals (Engel \& Tollrian 2009). In some cases, we 
might also be able to compare animal species in natural habitats where they co-occur or when they are kept under similar conditions in captivity, as is the case in many zoos.

We discussed the major types of comparison involving invasive species, but of course additional comparisons could be made and some of the species categories could be refined. For

and invasive species is not a strict dichotomy, but a continuum that could either be treated as such if information is available on the spread of each alien species (see Appendix S1 for an example), or could be incorporated by using intermediate categories such as 'casual' and 'naturalized' (Richardson et al. 2000); Colautti \& MacIsaac 2004). Furthermore, one could address more specific distinguishing among different types of invaders, such as invaders of anthropogenic habitats and invaders of natural areas, or invaders with ecosystem impacts and invaders without such impacts. Ultimately, the most complete picture of determinants of invasiveness will be achieved by combining all types of comparison among different species statuses and different ranges. However, even if it is not feasible to compare invasive alien species with all types of comparators in both the introduced and native range, it should be more widely acknowledged that the different types of comparison address different biological questions, and that some questions require multiple comparisons.

\section{ACKNOWLEDGEMENTS}

We thank Anne Kempel for providing the template of a flower symbols in Figs 1 and 2, Marcel Rejmánek and three anonymous referees for valuable comments on a previous version of the manuscript. We also thank the Swiss Science Foundation (grant 31003A-117722), the SinoSwiss Science and Technology Cooperation and the Swiss National Centre of Competence in Research - Plant Survival for funding.

\section{REFERENCES}

Alpert, P., Bone, E. \& Holzapfel, C. (2000). Invasiveness, invisibility and the role of environmental stress in the spread of nonnative plants. Perspect. Plant Ficol., 3, 52-66.

Baker, H.G. (1974). The evolution of weeds. Annu. Rev. Ficol. Syst., 5, 1-24.

Blackburn, T.M. \& Duncan, R.P. (20)1). Establishment patterns of exotic birds are constrained by non-random patterns in introduction. J. Biogeogr., 28, 927-939.

Blackburn, T.M. \& Jeschke, J.M. (2009). Invasion success and threat status: two sides of a different coin? Ficography, 32, 83-88.

Blackburn, T.M., Cassey, P. \& Lockwood, J.L. (2009). The role of species traits in the establishment success of exotic birds. Global Change Biol., 15, 2852-2860).
Blossey, B. \& Nötzold, R. (1995). Evolution of increased competitive ability in invasive nonindigenous plants: a hypothesis. J. Ficol., 83, 887-889).

Bossdorf, O., Auge, H., Lafuma, L., Rogers, W.E., Siemann, E. \& Prati, D. (20)5). Phenotypic and genetic differentiation between native and introduced plant populations. Oecologia, 144, 1-11.

Bucharova, A. \& van Kleunen, M. (2009). Introduction history and species characteristics partly explain naturalization success of North American woody species in Furope. J. Eicol., 97, 230238.

Buckley, Y.M., Downey, P., Fowler, S.V., Hill, R., Memmot, J., Norambuena, H. et al. (20)3). Are invasives bigger? A global study of seed size variation in two exotic shrubs. Eicology, 84, 1434-1440.

Burns, J.H. (2008). Demographic performance predicts invasiveness of species in the Commelinaceae under high-nutrient conditions. Eicol. Appl., 18, 335-346.

Callaway, R.M. \& Aschehoug, E.T. (200)). Invasive plants versus their new and old neighbors: a mechanism for exotic invasion. Science, 290), 521-523.

Cassey, P., Blackburn, T.M., Jones, K.E. \& Lockwood, J.L. (20)4a). Mistakes in the analysis of exotic species establishment: source pool designation and correlates of introduction success among parrots (Aves: Psittaciformes) of the world. J. Biogeogr, 31, 277284.

Cassey, P., Blackburn, T.M., Sol, D., Duncan, R.P. \& Lockwood, J.L. (2004b). Global patterns of introduction effort and establishment success in birds. Proc. R. Soc. B, 271, S405-S408.

Catford, J.A., Jansson, R. \& Nilsson, C. (2009)). Reducing redundancy in invasion ecology by integrating hypotheses into a single theoretical framework. Divers. Distrib., 15, 22-40.

Chapman, J.W., Miller, T.W. \& Coan, E.V. (2003). Life seafood species as recipes for invasion. Conserv. Biol., 17, 13861395.

Colautti, R.I. (20)5). Are characteristics of introduced salmonid fishes biased by propagule pressure? Can. J Aguat. Sci., 62, 950959.

Colautti, R.I. \& MacIsaac, H.J. (20()4). A neutral terminology to define 'invasive' species. Diversity Distrib., 10, 135-141.

Colautti, R.I., Ricciardi, A., Grigorovich, I.A. \& Maclsaac, H.J. (2004). Is invasion success explained by the enemy release hypothesis? Ficol. Iett., 7, 721-733.

Cox, G.W. (2004). Alien Species and Eivolution: 7he Fivolutionary Eicology of Fixotic Plants, Animals, Microbes, and Interacting Native Species. Island Press, Washington, DC, LSA.

Crawley, M.J. (1987). What makes a community invasible? In: Colonization, Succession and Stability (eds Gray, A.J., Crawley, M.J. \& Fdwards, P.J.). Blackwell Scientific Publications, Oxford, LK, pp. 429-453.

Dang, C., de Montaudouin, X., Bald, J., Jude, F., Raymond, N., Lanceleur, L. et al. (20(9)). Testing the enemy release hypothesis: trematode parasites in the non-indigenous Manila clam Ruditapes philippinarum. Hydrobiologia, 630, 139-148.

Davis, M.A., Grime, J.P. \& Thompson, K. (2000). Fluctuating resources in plant communities: a general theory of invasibility. J. Ficol., 88, 528-534.

Daws, M.I., Hall, J., Flynn, S. \& Pritchard, H.W. (20)7). Do invasive species have bigger seeds? Fvidence from intra- and inter-specific comparisons. S. Afr. J. Bot., 73, 138-143. 
Dawson, W., Burslem, D.F.R.P. \& Hulme, P.E. (2009a). Herbivory is related to taxonomic isolation, but not to invasiveness of tropical alien plants. Divers. Distrib., 15, 141-147.

Dawson, W., Burslem, D.F.R.P. \& Hulme, P.E. (2009b). Factors explaining alien plant invasion success in a tropical ecosystem differ at each stage of invasion. J. Eicol., 97, 657-665.

Dehnen-Schmutz, K., Touza, J., Perrings, C. \& Williamson, M. (2007). A century of the ornamental plant trade and its impact on invasion success. Divers. Distrib., 13, 527-534.

DeWalt, S.J., Denslow, J.S. \& Ickes, K. (2004). Natural-enemy release facilitates habitat expansion of the invasive tropical shrub Clidemia birta. Ecology, 85, 471-483.

Dietz, H. \& Edwards, P.J. (2006). Recognition that causal processes change during plant invasion helps explain conflicts in evidence. Eiology, 87, 1359-1367.

Diez, J.M., Sullivan, J.J., Hulme, P.E., Edwards, G. \& Duncan, R.P. (2008). Darwin's naturalization conundrum: dissecting taxonomic patterns of species invasions. Ecol. Lett., 11, 674-681.

Ellstrand, N.C. \& Schierenbeck, K.A. (2000). Hybridization as a stimulus for the evolution of invasiveness in plants? Proc. Natl. Acad. Sci. USA, 97, 7043-7050.

Engel, K. \& Tollrian, R. (2009). Inducible defences as key adaptations for the successful invasion of Daphnia lumboltri in North America? Proc. R. Soc. B., 276, 1865-1873.

Flory, S.L. \& Clay, K. (2009)). Effects of roads and forest successional age on experimental plant invasions. Biol. Conserv., 142, 2531-2537.

Gravuer, K., Sullivan, J.J., Williams, P.A. \& Duncan, R.P. (2008). Strong human association with plant invasion success for Trifolium introductions to New Zealand. Proc. Natl. Acad. Sci. USA, 105, 6344-6349)

Grotkopp, E. \& Rejmánek, M. (2007). High seedling relative growth rate and specific leaf area are traits of invasive species: phylogenetically independent contrasts of woody angiosperms. Am. J. Bot., 94, 526-532.

Hamilton, M.A., Murray, B.R., Cadotte, M.W., Hose, G.C., Baker, A.C., Harris, C.J. et al. (2005). Life-history correlates of plant invasiveness at regional and continental scales. Eicol. Iett., 8, 1066-1074.

Hänfling, B. (2007). Understanding the establishment success of non-indigenous fishes: lessons from population genetics. J. Fish Biol., 71, 115-135.

Hierro, J.L., Maron, J.L. \& Callaway, R.M. (2005). A biogeographical approach to plant invasions: the importance of studying exotics in their introduced and native range. J. Ecol., 93, $5-15$.

Huey, R.B., Gilchrist, G.W. \& Hendry, A.P. (2005). Using invasive species to study evolution: case studies with Drosopbila and salmon. In: Species Invasions: Insights into Ecology, Evolution, and Bio. geography (eds Sax, D.F., Stachowicz, J.J. \& Gaines, S.D.). Sinauer, Sunderland, MA, LSA, pp. 139-164.

Hulme, P.E., Bacher, S., Kenis, M., Klotz, S., Kühn, I., Minchin, D. et al. (2008). Grasping the routes of biological invasions: a framework for integrating pathways into policy. J. Appl. licol., 45, $403-414$

Jeschke, J.M. \& Strayer, D.L. (2006). Determinants of vertebrate invasion success in Europe and North America. Global Change Biol., 12, 1608-1619.

Jeschke, J.M. \& Strayer, D.L. (2008). Are threat status and invasion success two sides of the same coin? Ecography, 31, 124-130.
Keller, S.R. \& Taylor, D.T. (2008). History, chance and adaptation during biological invasion: separating stochastic phenotypic evolution from response to selection. Ficol. Lett., 11, 852-866.

van Kleunen, M. \& Fischer, M. (2008). Adaptive rather than nonadaptive evolution of Mimulus guttatus in its invasive range. Basic Appl. ticol., 9, 213-223.

van Kleunen, M. \& Fischer, M. (2009). Release from foliar and floral fungal pathogen species does not explain the geographic spread of naturalized North American plants in Europe. J. Eicol., 97, 385-392.

van Kleunen, M. \& Richardson, D.M. (2007). Invasion biology and conservation biology - time to join forces to explore the links between species traits and extinction risk and invasiveness. Prog. Phys. Geog., 31, 447-450.

van Kleunen, M., Johnson, S.D. \& Fischer, M. (2007). Predicting naturalization of southern African Iridaceae in other regions. $J$. Appl. Eicol., 44, 594-603.

van Kleunen, M., Weber, E. \& Fischer, M. (2010). A meta-analysis of trait differences between invasive and non-invasive plant species. Licol. Iett., 13, 235-245.

Klotz, S., Kühn, I. \& Durka, W. (2002). BIOIfILOR - Eine Datenbank z" Biologisch-Ökologischen Merkmalen der Gefässpfanzen in Deutscbland. Scbrifireibe für Vegetationskunde 38. Bündesamt für Naturschutz, Bonn, Germany.

Kolar, C.S. \& Lodge, D.M. (2001). Progress in invasion biology: predicting invaders. Trends Ficol. Fivol., 16, 199-204.

Kowarik, I. (1995). Time lags in biological invasions with regard to the success and failure of alien species. In: Plant Imvasions General Aspects and Special Problems (eds Pyšek, P., Prach, K., Rejmánek, M. \& Wade, M.). SPB Academic Publishing, Amsterdam, the Netherlands, pp. 15-38.

Lake, J.C. \& Leishman, M.R. (2004). Invasion success of exotic plants in natural ecosystems: the role of disturbance, plant attributes and freedom from herbivores. Biol. Conserv., 117, 215226.

Larson, E.R. \& Magoulick, D.D. (2009). Does juvenile competition explain displacement of a native crayfish by an introduced crayfish? Biol. Invasions, 11, 725-735.

Lee, K.A., Martin, L.B. Il \& Wikelski, M.C. (2005). Responding to inflammatory challenges is less costly for a successful avian invader, the house sparrow (Passer domesticus), than its less-invasive congener. Oecologia, 145, 244-251.

Leishman, M.R. \& Thomson, V.P. (2005). Experimental evidence for the effects of additional water, nutrients and physical disturbance on invasive plants in low fertility Hawkesbury Sandstone soils, Sydney, Australia. J. Ecol., 93, 38-49.

Leishman, M.R., Thomson, V.P. \& Cooke, J. (2010). Native and exotic invasive plants have fundamentally similar carbon capture strategies. J. Ecol., 98, 28-42.

Liu, H. \& Stiling, P. (2006). Testing the enemy release hypothesis: a review and meta-analysis. Biol. Invasions, 8, 1535-1545.

Lockwood, J.L., Cassey, P. \& Blackburn, T. (2005). The role of propagule pressure in explaining species invasions. Trends Eicol. Evol., 20, 223-228.

Mack, R.N. (1996). Predicting the identity and fate of plant invaders: emergent and emerging approaches. Biol. Conserl., 78, $107-121$.

Maron, J.L., Vila, M., Bommarco, R., Elmendorf, S. \& Beardsley, P. (2004). Rapid evolution of an invasive plant. Eicol. Monogr., 74, 261-280. 
Martin, P.H., Canham, C.I). \& Marks, P.L. (200)9). Why forests appear resistant to exotic plant invasions: intentional introductions, stand dynamics, and the role of shade tolerance. Frontiers Ecol. Environ., 7, 142-149.

Mason, R.A.B., Cooke, J., Moles, A.T. \& Leishman, M.R. (20)8) Reproductive output of invasive versus native plants. Global Ficol. Biogeogr:, 17, 633-640.

Mitchell, C.E. \& Power, A.G. (2003). Release of invasive plants from fungal and viral pathogens. Nature, 421, 625-627.

Moloney, K.A., Holzapfel, C., Tielbörger, K., Jeltsch, F. \& Schurr, F.M. (20(5)). Rethinking the common garden in invasion research. Perspect. Plant Ficol., 11, 311-320.

Muth, N.Z. \& Pigliucci, M. (200)6). Traits of invasives reconsidered: phenotypic comparisons of introduced invasive and introduced noninvasive plant species within two closely related clades. $1 \mathrm{~m}$. J. Bot., 93, 188-196.

Pyšek, P. \& Richardson, D.M. (2007). Traits associated with invasiveness in alien plants: where do we stand? In: Biological Invasions (ed Nentwig, W.). Springer-Verlag, Berlin, Germany, pp. 97-125.

Pyšek, P., Prach, K. \& Šmilauer, P. (1995). Relating invasion success to plant traits: an analysis of the Czech alien flora. In: Plant Invasions - General 1spects and Special Problems (eds Pyšek, P., Prach, K., Rejmánek, M. \& Wade, M.). SPB Academic Publishers, Amsterdam, the Netherlands, pp. 39-60.

Pyšek, P., Richardson, D.M. \& Williamson, M. (20)4). Predicting and explaining plant invasions through analysis of source area floras: some critical considerations. Divers. Distrib., 10, 179_ 187.

Rejmánek, M. (1999)). Invasive plant species and invasible ecosystems. In: Invasive Species and Biodiversity Management (eds Sandlund, O.T., Schei, P.J. \& Viken, Á). Kluwer Academic Publishers, Dordrecht, the Netherlands, pp. 79-102.

Richards, C.L., Bossdorf, O., Muth, N.Z., Gurevitch, J. \& Pigliucci, M. (2006). Jack of all trades, master of some? On the role of phenotypic plasticity in plant invasions. Eicol. Iett., 9, $981-993$.

Richardson, D.M. \& Pyšek, P. (20)8). Fifty years of invasion ecology - the legacy of Charles Elton. Divers. Distrib., 14, 161168.

Richardson, D.M., Pyšek, P., Rejmánek, M., Barbour, M.G., Panetta, F.D. \& West, C.J. (200)). Naturalization and invasion of alien plants: concepts and definitions. Divers. Distrib., 6, 93107.

Richardson, D.M., Rouget, M. \& Rejmánek, M. (2004). Using natural experiments in the study of alien tree invasions. In: Experimental Approaches to Conservation Biology (eds Gordon, M.S. \& Bartol, S.M.). University of California Press, Berkeley, CA, USA, pp. 180-201.
Schlaepfer, D.R., Edwards, P.J., Widmer, A. \& Billeter, R. (2008). Phylogeography of native ploidy levels and invasive tetraploids of Solidago gigantea (Asteraceae). Mol. Ficol., 17, 5245-5256.

Schlaepfer, D.R., Glättli, M., Fischer, M. \& van Kleunen, M. (2010). A multi-species experiment in their native range indicates pre-adaptation of invasive alien plant species. Nen Phytol., 185, 1087-1099.

Strauss, S.Y., Webb, C.O. \& Salamin, N. (2006). Exotic taxa less related to native species are more invasive. Proc. Natl. Acad. Sci. U.SA, 103, 5841-5845

Tecco, P.A., Diaz, S., Cabido, M. \& Urcelay, C. (2010). Functional traits of alien plants across contrasting climatic and land-use regimes: do aliens join the locals or try harder than them? J. Eicol., 98, 17-27.

Thébaud, C. \& Simberloff, D. (20)1). Are plants really larger in their introduced ranges? Am. Nat., 157, 231-236.

Thompson, K., Hodgson, J.G. \& Rich, T.C.G. (1995). Native and alien invasive plants: more of the same? Ficograpby, 18, 390-402.

Torchin, M.F., Lafferty, K.D. \& Kuris, A.M. (2001). Release from parasites as natural enemies: increased performance of a globally introduced marine crab. Biol. Invasions, 3, 333-345.

Torchin, M.E., Lafferty, K.D., Dobson, A.P., Mckenzie, V.J. \& Kuris, A.M. (2003). Introduced species and their missing parasites. Nature, 421, 628-630.

Westoby, M., Leishman, M.R. \& Lord, J.M. (1995). On misinterpreting the 'phylogenetic correction'. J. Ecol., 83, 531-534.

\section{SUPPORTING INFORMATION}

Additional Supporting Information may be found in the online version of this article:

Appendix S1 Quantitative comparison of height between alien and native species of Asteraceae varying in their abundance in Germany.

As a service to our authors and readers, this journal provides supporting information supplied by the authors. Such materials are peer-reviewed and may be re-organized for online delivery, but are not copy-edited or typeset. Technical support issues arising from supporting information (other than missing files) should be addressed to the authors. 